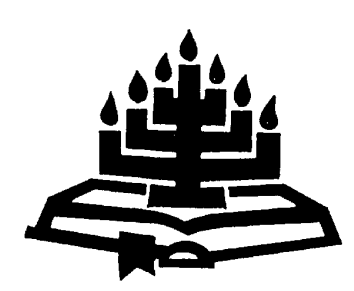

\title{
Die oorsake van anti-Semitisme in die antieke heidenwêreld in en rondom die Nuwe-Testamentiese tydvak
}

Andrie du Toit

Navorsingeenheid vir Nuwe Testament

Departement Nuwe Testament (B)

Universiteit van Pretoria

PRETORIA

E-pos: latoit@ccnet.up.ac.za

\begin{abstract}
The causes of anti-Semitism in ancient paganism in and around the New Testament period

In this article the causes of ancient anti-Semitism are investigated. This is not a mere academic quest, since some of these factors may still be relevant today. After discussing some methodological pitfalls, various causes are identified, some of which were limited to specific areas. Where the balance of power was felt to be in jeopardy, groups reacted strongly. Ensuing clashes aggravated the resentment and caused anti-Semitism to become still more deeply engrained in the collective memory. In Alexandria economic rivalry probably was a factor. In Rome Jewish propagandistic zeal and Roman pride influenced attitudes. The Egyptian vilification implying that the Jewish nation originally was contaminated by a disease, further negativized attitudes. However, the main causes of anti-Semitism were of a sociological (the Jewish $\alpha \mu 1 \xi i \alpha$ ) and religious nature. These two causes are related, but at its deepest level ancient anti-Semitism was the price the Jewish people paid for its refusal to compromise its religious convictions and unique identity. In how far the causes of modern anti-Semitism overlap with those of antiquity should be investigated on its own.
\end{abstract}

\section{Inleidend}

In die vorige artikel (Du Toit, 1999:21-37) is gekyk na die beginspore van antiSemitisme in die tydperk tot ongeveer 150 v.C. Vervolgens is die sterk verspreiding en omvang van anti-Semitisme vanaf 150 v.C. onder die loep geneem. Die belangrike vraag wat nou gestel moet word, is dié na die faktore wat 
antieke anti-Semitisme veroorsaak het. Hierdie is geen bloot akademiese vraagstelling nie, aangesien sekere van hierdie faktore ook in moderne manifestasies van anti-Semitisme 'n rol kan speel.

\section{Die oorsake van antieke anti-Semitisme}

Sevenster (1975:36-88) het duidelik aangetoon hoe metodologies totaal foutief dit is om ons moderne persepsies van anti-Semitisme - wat natuurlik maar die produk is van tradisies en gebeure uit ons eie verlede en kollektiewe geheue - op die antieke tyd oor te dra. Dit kan toegelig word aan die hand van twee voorbeelde:

Eerstens: Moderne manifestasies van anti-Semitisme vertoon dikwels rassistiese patrone. In die eerste-eeuse anti-Semitisme was dit geensins die geval nie. Reeds Leipoldt (1950: kol. 470) het daarop gewys dat "rassemässiges Empfinden" by die mens van die Hellenisties-Romeinse tyd slegs 'n baie geringe rol gespeel het (insgelyks Holsten, 1957: kol. 456). In 'n breë ondersoek het ook Sevenster (1975:36-56) bevind dat biologiese verskille in die destydse sosiale opset geen besondere rol gespeel het nie, maar wel verskille op grond van beskawing, geleerdheid en sosiale stand. Wat die Jode betref, is dit opvallend dat hulle nie gehuiwer het om proseliete, synde persone uit ander groepe wat ten volle tot die Joodse geloof oorgegaan het, as deel van die Joodse volk te beskou nie. Ons weet byvoorbeeld uit grafskrifte in Rome dat proseliete in die Joodse kerkhowe begrawe is. Ten opsigte van die Romeine wys Sevenster daarop dat Sisero in sy tirade teen die Jode nêrens 'n rasverwante opmerking maak nie: "What he does not do is to speak of them as a distinctive race with distinctive external or internal characteristics. He would certainly have done so in this instance, if these had formed contributing factors to the contempt and scorn of the Jews" (Sevenster, 1975:51).

Dieselfde geld vir die ekonomiese magsfaktor. In Nazi-propaganda is tot vervelens toe gehoor van die Joodse geldmag wat die gewone landsburgers uitgebuit het. In die vroegste fase van die anti-Semitisme was dit egter nog nie die geval nie, al het verskeie resente skrywers sonder die nodige dokumentasie hierdie soort stelling gemaak. Bousset en Gressmann (1966:75) identifiseer byvoorbeeld sonder meer Jode se rykdom en verdagte handelspraktyke as van die belangrikste oorsake van anti-Semitisme (vir ander skrywers kyk by Sevenster, 1975:57 e.v.). Sevenster self kom egter tot 'n heeltemal ander gevolgtrekking. Hy behandel die ekonomiese posisie van die Jode in die Diaspora breedvoerig en bevind dan dat hulle, oor die geheel beskou, geen welvarender groep as diegene rondom hulle was nie. Daar was wel welgesteldes onder hulle, maar dan soos in elke ander gemeenskap; trouens hulle het die volle ekonomiese spektrum verteenwoordig en daarom was daar geen rede waarom die nie-Jode hulle hulle welvaart sou beny nie (Sevenster, 1975:57-88). Heinemann (1931: kol. 40 e.v.) 
het reeds in 1931 bevind dat die Joodse volk sedert die keisertyd eerder deur armoede as deur rykdom gekenmerk was en dat hulle destyds geen besondere handelsvolk was nie. Tcherikover en Fuks (1957:I:19) het ten opsigte van Egipte tot dieselfde konklusie gekom en verklaar dat, afgesien van die beperkte aantal rykes, die Jode van Egipte merendeels die indruk geskep het van "a hard-working people earning its living by tenacious labour". Hierdie faktor is trouens ook nie een van die verwyte wat normaalweg aan die Joodse adres gerig was nie. Die enigste uitsondering was waarskynlik Aleksandrië (vide infra). Hier het die ekonomiese magsfaktor vermoedelik wel 'n rol gespeel (vgl. ook Sevenster, 1975:88).

Soos reeds hierbo uit die geval van Aleksandrië blyk, sou dit metodologies ook heeltemal verkeerd wees om sonder meer van die standpunt uit te gaan dat antiJoodse houdings oral presies dieselfde wortels moes gehad het. Teoreties moet die moontlikheid oopgehou word dat die veroorsakende faktore in sekere gevalle gemeenskaplik kon gewees het, maar in ander gevalle weer uiteenlopend en geografies spesifiek.

Die belangrikste rigtingwysers na die oorsake van anti-Semitisme moet gevind word by die verskillende negatiewe karakteriserings in die geskrewe dokumente wat behoue gebly het. Alhoewel skrywers en digters nie noodwendig altyd 'n suiwer barometer van groepe se gevoelens is nie, is dit tog heel dikwels die geval en ons het geen rede om te oordeel dat dit ten opsigte van die Jode anders was nie. Dit is egter ook nie noodwendig so dat die geformuleerde oppervlakaanduidings, in hierdie geval die onderskeie vorms van vilifikasie, innerlike gesindhede presies raakvat nie. Daarom sal ons by geleentheid ook moet vra na wat agter 'n bepaalde formulering lê.

Soos ons reeds gesien het, kom die oudste vorm van Joodse swartsmeerdery waarskynlik uit Egipte. Die Egiptiese tradisie wat Hekataius aanhaal (kyk Du

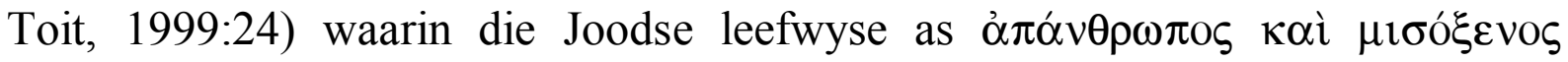
gekarakteriseer word, loop soos 'n goue draad deur die eeue. Hierdie verwyt dat die Jode hulleself doelbewus afsonder, word op verskillende maniere geformuleer (afsydigheid, vreemdelinghaat, mensehaat ens.), maar kom voor van Egipte tot in Babilonië, van Sirië tot in Rome. In Egipte kry ons dit ook nog by Maneto (kyk by Josefus, $A p$. 1.239). Lisimagus verklaar dat Moses aan die Jode opdrag gegee het om geen welwillendheid aan ander te betoon nie en aan hulle net die slegste advies te gee (Josefus, $A p$. 1.309). In Babilonië hoor ons van die Joodse "apartheid" uit die mond van Haman (Est. 3:8). By Posidonius van Apamea in Sirië kry ons van die heel sterkste verwyte van hierdie aard. Hy beskuldig die Jode onomwonde van mensehaat. Hy verklaar dat hulle kontak met ander mense vermy; dat hulle alle mense as hulle vyande beskou en weier om saam met ander te eet (by Diodorus, Bibl. Hist. 34.1.1-5). Apollonius Molon herhaal die beskuldiging van mensehaat en mensemyding (by Josefus, Ap. 2.148,258). 
In Rome self kom die beskuldiging van mensehaat as sodanig nie by Sisero voor nie, maar hy beklemtoon hoe die Jode altyd saamgroepeer en so 'n drukgroep vorm (Pro Flacc. 28.66-69). Pompeius Trogus, die Romeinse historikus uit die Augustynse tydvak, is die eerste Romeinse skrywer wat die Joodse afsydigheid in soveel woorde vermeld. Hy tipeer dit as 'n godsdienstige voorskrif (by Justinus, Hist. Philip. 36.2.16). Soos Sisero beklemtoon ook Tasitus die onderlinge lojaliteit van die Jode, maar striem vervolgens hulle bittere vyandigheid teen alle mense (adversus omnes alios hostile odium (Hist. 5.5.1 e.v.). Die beskuldiging van $\alpha \mu \imath \xi i \alpha$ leef vir eeue voort. In die derde eeu kry ons dit nog by Filostratus (Vit. Apol. 5.33). Joodse skrywers uit die eerste eeu was wel deeglik bewus van hierdie tipe beskuldiging en Josefus sowel as Filo het hulle daarteen verweer (vgl. Josefus, Ap. 2.211,283,291; Filo, Virt. 141; Spec. Leg 2.167; 3.36,110,113, 119).

Waar die $\alpha \dot{\alpha} \mu \xi \xi^{\prime} \alpha$-beskuldiging op die sosiale vlak lê, was 'n ander strategie om 'n klad op die Joodse volk se historiese herkoms te plaas. Die stelling dat die Jode oorspronklik 'n groep melaatses was wat uit Egipte verdryf is, word in verskillende variasies herhaal en het waarskynlik sy oorsprong in 'n geniepsige Egiptiese reaksie op die Joodse uittogverhaal gehad (kyk Du Toit, 1999:24). Hierdie beswaddering (soms met vermelding van ' $\mathrm{n}$ ander besmetting, soms slegs met verwysing na Moses) het 'n geografies meer beperkte maar tog hardnekkige bestaan gevoer. In Egipte kry ons dit nie net by Maneto nie, maar ook by Lisimagus (by Josefus, Ap. 1.304-311), Apion (by Josefus, Ap. 2.8,15), Gaeremon (by Josefus, Ap. 1.288-290), Nikargus (by Fotius, Lexicon s.v. "A $\lambda \varphi \alpha$ ), Ptolemeus Gennus in die tweede eeu n.C. (by Fotius, Bibl., p.151b) en selfs nog in die vierde eeu by Helladius (Chrestom. by Fotius, Cod. 279, p.529b). In Sirië verskyn dit by Posidonius (vgl. Diodorus, Bibl. Hist. 34-35.1.2), in die nabygeleë Fenisia by Herrenius (o.a. by Helladius, Chrestom.) en in Rome by Pompeius Trogus (by Justinus, Hist. Philip. 36.2.12) en Tasitus (Ann. 3.1). Dis ook te begrype dat hierdie soort belediging allermins daartoe bygedra het om Joodse gemoedere positief teenoor hulle nie-Joodse landgenote te stem.

'n Derde vorm van beswaddering lê op religieuse terrein. Soos by die $\alpha \mu t \xi i ́ \alpha-$ groep het ons hier ook 'n hele konglomeraat van formulerings, maar hierdie keer val die fokus op die Jode se godsdiens en hulle lewenstyl. Die feit dat die Jode 'n onsigbare God aanbid het en die heidense gode en afgodsbeelde verwerp het, het tot allerlei misverstande en karikatuurvoorstellings aanleiding gegee. Een hiervan

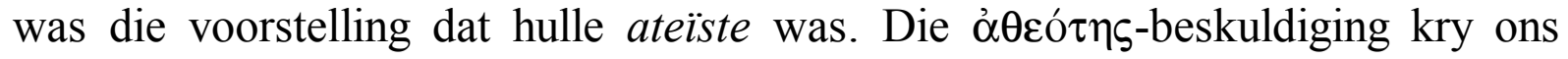
onder meer by Apollonius Molon (by Josefus, Ap. 2.148), die ouer Plinius (Nat. Hist. 13.46), Tasitus (Hist. 5.5 [ contemnere deos]), Dio Kassius (Hist. Rom. 67.14.2) en in die vierde eeu by Julianus (Contr. Gal. 43B) - 'n beskuldiging wat ook die Christene sou tref (vgl. Stern 1980:545). 'n Aanklag wat hierby aansluit, was dié van superstitio (Sisero, Pro Flacc. 28.67; Kwintilianus, Inst. Or. 3.7.21; Plutargus De Superst. 3, p.166A; 8, p.169C; Tasitus, Hist. 5.8.2;13.1; Ann. 
2.85.4; Agatargides by Josefus, Antiq. 12.5-6; vir ander voorbeelde kyk Stern, 1976:547; 1980:60). Dit geld ook van die verwyt van goddeloosheid ( $\alpha \sigma \varepsilon \hat{\beta} \beta 1 \alpha)$ (by Diodorus, Bibl. Hist. 34-35.1.2; vgl. Dio Kassius, Hist. Rom. 68.1.2; Julianus Contr. Gal. 238B; Ad. Com. Iud.) en Juvenalis se stelling dat die Jode die wolke en hemele aanbid (Sat. 14.97). Goodman (1986:611-613) toon aan hoe die Joodse apologete hulle teen hierdie bewerings moes verweer, alhoewel nie al sy verwysings ewe oortuigend is nie.

Die lasterlikste aftakeling op religieuse terrein was ongetwyfeld dié van eselsaanbidding wat verspreid oor drie eeue voorkom by Mnaseas, Apollonius Molon, Posidonius, Damokritus, Apion, Plutargus en Tasitus (vgl. byvoorbeeld Josefus, Ap. 2,80-88,114 e.v.,120; meer hieroor by Sevenster, 1975:8-11).

Die andersheid en eksklusivisme van die Joodse godsdiens het ook nog allerlei verregaande spekulasie meegebring ten opsigte van wat in hulle kultus plaasvind. Een van die beskuldigings in hierdie verband was dié van rituele moord. Die Jode sou volgens Apion periodiek 'n nie-Jood kulties geslag, geoffer en van sy vleis

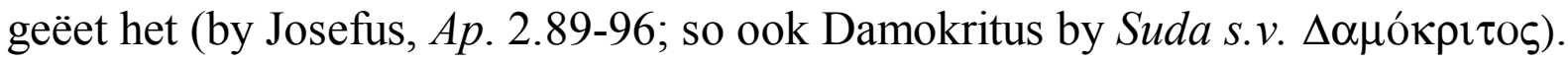
Hierdie soort verhaal het ' $n$ baie tragiese nasleep in die latere Joodse geskiedenis gehad (vgl. Sevenster, 1975:140).

Sekere aspekte van die Joodse ethos het ook in die spervuur gekom, naamlik die besnydenis, die Sabbat en hulle weerhouding van varkvleis. Die Jode was nie die enigste volk in die Middellandse Seegebied wat die besnydenis beoefen het nie. Tog was die besnydenis vir hulle besonder belangrik. Wanneer nie-Joodse skrywers oor die Joodse besnydenis geskrywe het, was dit feitlik altyd op 'n neerhalende wyse (Sevenster, 1975:132-136). Filo sowel as Josefus reageer skerp hierop (Filo, Spec. Leg. 1.1 e.v.; Josefus, Ap. 2.137,142 e.v.).

Die Joodse Sabbatviering was vir Juvenalis 'n duidelike bewys van luiheid (Sat. 6.60) en Seneka het dit gesien as 'n vermorsing van 'n sewende deel van 'n mens se lewe (Ep. Mor. 95.57). Juvenalis spot met die gaafheid van die Jode om aan varke 'n lang lewe te besorg (Sat. 6.60).

Nie alle nie-Jode is egter deur die Joodse geloof en leefwyse afgestoot nie. Die keersy van die munt is dat talle juis deur die kwaliteit van die Joodse godsdienstige oortuigings aangetrek is. Die geloof in een, unieke, onsigbare, heilige God van hemel en aarde, die gesagsaanspraak van die Joodse godsdienstige boeke, die Joodse volk se hoogstaande etiese kode - hierdie dinge het meegebring dat veral in die eerste eeu na Christus heelwat godvresendes en ook 'n aantal proseliete hulle by die sinagoge geskaar het (vgl. Du Toit, 1997:502). Hierby kom ook nog die aktiewe Joodse propaganda (vgl. Du Toit, 1997:502504). In Rome het hierdie Joodse propaganda egter ook weer negatiewe reaksie 
opgewek, soos blyk by veral sekere Romeinse skrywers (Sevenster, 1975:203 e.v.; Du Toit, 1997:505).

Vanweë die onverbiddelike wyse waarop die Jode aan hulle godsdiens vasgehou het en die militêre en politieke implikasies daarvan moes die Romeinse owerhede besluit om hulle óf tegemoet te kom óf 'n nimmereindigende reeks konfrontasies tegemoet te gaan. Julius Sesar het in sy wysheid op eersgenoemde besluit. Hierdie besondere bevoorregting van die Jode wat, soos ons reeds gesien het, telkens deur die sentrale owerheid herbevestig is, het op sy beurt weer die haat en afguns van hulle bure op plaaslike vlak meegebring (Sevenster, 1975:145 e.v.). Vir die wêreld van destyds wat óf sinkretisties gedink het óf rustig aanvaar het dat verskillende godsdienste elkeen in eie reg langs mekaar kon bestaan, was die Joodse godsdienstige eksklusivisme, wat geen ander godheid erken het nie, wat hulleself as die uitverkore volk en alle nie-Jode as onrein beskou het, nie slegs volledig onaanvaarbaar nie, maar ook ondraaglik arrogant (vgl. Sevenster, 1975:215 e.v.). Dat die sentrale owerheid nog boonop deur wetgewing legitimiteit aan hierdie arrogansie verleen het, was 'n bitter pil om te sluk.

Die Joodse godsdienstige oortuigings het uiteraard ook meegebring dat hulle onverbiddelik geweier het om die keiser te aanbid. 'n Mens kan hier maar net dink aan die oorweldigende Joodse reaksie teen Kaligula se optrede. Die amptelike vergunnings wat hulle van die owerheid ontvang het, het hulle weliswaar ook op hierdie gebied beskerm, maar dit het nie uitgesluit dat hulle van dislojaliteit beskuldig, verdag gemaak en as swak landsburgers uitgekryt is nie (vgl. Tasitus, Hist. 5.5; Apion by Josefus, Ap. 2.65,68,73) . Die Joodse houding het des te meer opgeval omdat die provinsies as't ware oormekaar geval het om die keiser te vereer. Dit is beskou as die groot maatstaf vir lojaliteit aan Rome (Goodman, 1986:613).

Die feit dat die Jode so hardnekkig aan hulle godsdienstige oortuigings en gebruike vasgehou het, beteken nie dat daar nie ook uitsonderings was nie. Vir sommige het die druk van buite te sterk geword en hulle het aan die versoeking tot assimilasie toegegee. Sevenster (1975:73-75, 112-114, 175) noem 'n hele aantal gevalle van Jode wat hulle op hierdie wyse gekompromitteer het. Een van die markantste voorbeelde was dié van Tiberius Aleksander wat volgens Tasitus 'n Romeinse ridder geword het en op 'n stadium die prefek van Egipte was (Ann. 15.28; Hist. 1.11). Van hom sê Josefus dat hy nie by sy voorvaderlike gebruike gebly het nie (Antiq. 20.100). Dit bly egter 'n historiese feit dat die oorgrote meerderheid van die Joodse volk bekend gestaan het vir hulle onwrikbare lojaliteit teenoor God en sy Wet.

Ons het reeds daarop gewys dat dit metodologies heeltemal verkeerd sou wees om die antieke anti-Semitisme vanuit ons moderne sienings te beoordeel. Dit geld ook vir ons huidige persepsie dat die Jode, soos in die talle pogroms wat uit die 
geskiedenis bekend is, altyd die passiewe slagoffers was. Die Jode van die eerste eeue was geensins altyd mak lammers wat ter slagting gelei is nie. Hulle optrede het gewoonlik saamgehang met getalleverhoudings. Waar hulle vergelykenderwys sterk in getalle en invloed was - vergelyk ook Israel vandag - het hulle dikwels sterk teenstand gebied en was hulle by geleentheid selfs die inisieerders van geweld. Voorbeelde hiervan is nie net die opstande in Palestina self nie, maar ook in Aleksandrië en Egipte. Sevenster (1975:16-18, 28 e.v., 166, 172-174) vermeld verskeie geleenthede waar die Jode in werklikheid die aggressors was (vgl. ook Leipoldt, 1950: kol. 473). In Rome daarenteen sou hulle dit nooit kon waag nie. Dat hierdie ervaring van Joodse geweld en selfs aggressie op sy beurt weer verdere bitterheid veroorsaak het, is vanselfsprekend (kyk bv. Leipoldt 1950: kol. 470). Ernstige botsings met die Jode het die reeds bestaande bitterheid verder versterk en is dieper in die kollektiewe bewussyn ingegraveer.

Die Jode het, soos ons reeds gesien het, in Egipte en veral in Aleksandrië 'n redelike sterk posisie van mag, veral ook van ekonomiese mag, opgebou. Waar ons elders geen aanduiding het dat Jode se ekonomiese mag en handelspraktyke hulle bure se argwaan en vyandskap opgewek het nie, is Aleksandrië waarskynlik 'n uitsondering. Twee dokumente wys in hierdie rigting. Dit gaan eerstens oor 'n papirusbrief van die handelaar Sarapion aan sy vriend of verteenwoordiger in Aleksandrië. Laasgenoemde verkeer in 'n geldelike krisis en soek naarstiglik na 'n uitweg. Sarapion gee hom advies, maar waarsku hom ten slotte: "Indien dit nie slaag nie ... pas (in elk geval) op vir die Jode" (Tcherikover \& Fuks, 19571965:II:34). Die vertolking van hierdie sinnetjie is uiters omstrede. Sommige beskou dit bloot as 'n waarskuwing in 'n tyd van botsings tussen nie-Jode en Jode; vir ander gaan dit om 'n waarskuwing teen die sogenaamde "geld-Jood" (Sevenster, 1975:34-35). Die term "geld-Jood" verwys na die veel later stereotipe van 'n tipiese Jood wat met sy geld 'n magspel bedryf en ander gewetenloos uitbuit. Hierdie kwaadwillige anakronisme pas hoegenaamd nie in die eersteeeuse konteks nie. Dit is egter nie uit te sluit dat hierdie papirusbrief 'n persepsie reflekteer waarvolgens mense versigtig moes wees vir die Joodse geldmag of hulle handelspraktyke nie (vgl. Leipoldt, 1950: kol. 472 e.v.; anders egter Heinemann, 1931 kol. 40; vgl. Sevenster, 1975:34 e.v.). 'n Tweede moontlike heenwysing in hierdie rigting is ' $\mathrm{n}$ formulering van keiser Klaudius in sy skrywe aan die inwoners van Aleksandrië. Hy rig hom op 'n stadium eers tot die nieJoodse bevolking van Aleksandrië en daarna tot die Jode. Hy beveel die Jode om hulle te weerhou van sekere bedrywighede en "die voordeel te benut van wat hulle besit, en in 'n stad wat nie hulle eie is nie, te geniet van die oorvloed van alle goeie dinge" (reëls 94 e.v.; by Bell, 1924:25). Bell vermoed dat ons in hierdie verwysing na die "oorvloed van alle goeie dinge" 'n eggo vind van die naywer wat die Griekse Aleksandryne teenoor hulle welvarende Joodse bure moes gevoel het (1925:11, nota 3; vgl. egter ook Sevenster, 1975:88). Dit is myns insiens heeltemal moontlik dat keiser Klaudius juis hier sinspeel op een van die klagtes 
wat die Griekssprekende Aleksandrynse afvaardiging na Rome teenoor hom geopper het.

Ons het ook reeds ten opsigte van Rome ' $\mathrm{n}$ voorbeeld gehad van vyandigheid van meer lokale aard, naamlik die Romeinse skrywers se reaksie teen Joodse propaganda. Sevenster vermeld nog enkele ander sodanige faktore. Die inherente trots van die Romein en sy veragting van uitlanders, gepaard met die vrees dat hulle die karakter van die tradisionele Romeinse samelewing sou oorweldig, het 'n belangrike rol gespeel (Sevenster, 1975:55). Hierdie reaksie het uiteraard nie net die Joodse bevolking van Rome geraak nie, maar ook die Siriërs, Egiptenaars en talle ander. In die geval van die Jode het dit egter gepaard gegaan met verskeie ander faktore, en was dit besonder hewig.

Teenoor hierdie voorbeelde uit Aleksandrië en Rome van lokaal-beperkte faktore wat anti-Joodse gesindhede gestimuleer het, was daar ander wat meer universeel van aard was. Dit geld veral dié van $\alpha_{\alpha} \mu \imath \xi \hat{\imath} \alpha$, wat op die sosiale vlak lê, en die godsdienstige aanklag in sy verskeidenheid formulerings.

Die vraag is of een van hierdie twee aanklagte nie meer prominent of basies was nie. In sy belangrike werk oor hierdie onderwerp wy Sevenster (1975:89-144) meer as vyftig bladsye aan wat hy noem die "vreemdheid" van die Jode, 'n klag dus wat primêr op die sosiale of sosiologiese terrein lê. Hy (Sevenster, 1975:94102) dui wel aan dat hierdie "vreemdheid" te wyte was aan die Jode se godsdienstige oortuigings, maar beskou sosiale vreemdheid tog as die groot steen des aanstoots (vgl. by Sevenster, 1975:218). Vir Holsten (1957:457) daarenteen bestaan daar geen twyfel dat die groot struikelblok vir nie-Jode die "religiöse Besonderheit" van die Joodse volk was nie.

Sevenster se formulering moet ietwat genuanseer word. Ons het gesien dat die sosiologiese klag op 'n verskeidenheid maniere geformuleer kon word. Dit gaan om verwyte soos die Jode se asosiale aard, hulle saamkliekery (Sisero), mensehaat, vreemdelingehaat ensomeer. Dit het dus nie soseer gegaan om die Jode se vreemdheid as sodanig nie, maar om hulle hantering van daardie vreemdheid: hulle halsstarrige onbereidheid om deel te word van en op te gaan in die massa, om gelykgeskakel te word, om hulle Joodse identiteit prys te gee.

Ons het gesien dat ook die religieuse aanklag talle uiteenlopende formulerings

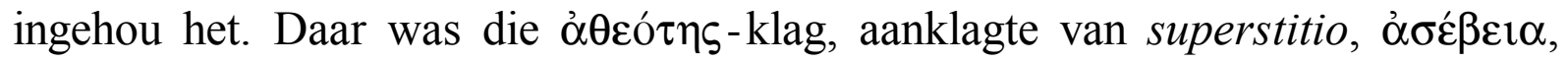
eselsaanbidding, barbaarse rituele, dislojaliteit aan die keiser en godsdienstige propaganda. Die Jode se oortuiging dat net hulle God die ware God was en dat alle heidense gode as verfoeilike afgode beskou en gehanteer moes word, dat net hulle godsdiens reg was en alle ander verkeerd, dat alle heidene godsdienstig onrein was, hulle weiering om in 'n andersins totaal sinkretistiese samelewing godsdienstig te amalgameer - al hierdie dinge is as ondraaglike arrogansie 
beskou. Daarby kom ook nog hulle vreemde en dikwels irriterende godsdienstige praktyke soos die besnydenis, die viering van die Sabbat en weiering om varkvleis te eet.

Ons moet egter probeer om die kernprobleem agter hierdie onderskeie religieuse aanklagte te identifiseer. Die so pas gemelde religieuse praktyke was beslis nie die kernprobleem nie. Vir buitestanders was hierdie gebruike meer eksentriek en amusant as wat dit vir hulle tot aanstoot was. Bewerings soos dié van eselsaanbidding en barbaarse rituele was kwaadwillig, maar sou as sodanig nie die buitestanders tot anti-Semitisme gedryf het nie. Die beskuldigings van dislojaliteit aan die keiser en godsdienstige propaganda was ook slegs uitlopers van die essensiële probleem.

Hierdie essensiële probleem het gelê in die uniekheids- en absoluutheidsaanspraak van die Joodse geloof. Omdat die God van die Jode die Gans Andere, die alleenware God was wat Hom op unieke wyse in die Ou-Testamentiese geskrifte geopenbaar het en deur sy Wet totale, eksklusiewe gehoorsaamheid van sy volk opgeëis het, moes hulle, midde onder die nasies, anders wees en anders optree. Hierdie besef van die unieke identiteit van hulle God, wat hulle tot sy verbondsvolk uitverkies het en deur sy openbaring en veral sy Wet sy uniekheidstempel op hulle afgedruk het, het aan die Jode hulle spesiale identiteitsbesef gegee. Hierdie identiteitsindikatief was tegelyk ook 'n identiteitsimperatief wat hulle totale optrede bepaal het: na binne as gemeenskap, maar ook na buite in alle sosiale verhoudings. Voeg daarby dat hulle, vanuit hierdie Godsverhouding, alle nie-Jode as onrein beskou het en daarom so ver as moontlik alle kontak met hulle moes vermy. Hier moet die basiese oorsaak van die nie-Jode se klag teen hulle Joodse bure gesoek word.

Dit het derhalwe geen sin om die sosiologiese en die religieuse klag teen mekaar uit te speel nie. Hulle is in werklikheid twee kante van dieselfde munt. Die meer fundamentele was egter die Joodse godsdiens. Dit het immers hulle sosiale optrede bepaal. Op die konkrete, alledaagse kontakvlak van mens tot mens was dit nietemin die Jode se vreemdsoortige optrede wat die meeste opgeval het en wat maklik as asosiaal geïnterpreteer kon word.

\section{Konklusie}

Ons kon 'n hele verskeidenheid oorsake vir die antieke anti-Semitisme identifiseer. Sommige daarvan was lokaal gebonde. In sekere Palestynse gebiede en Aleksandrië waar die Joodse posisie relatief sterk was, is hulle teenwoordigheid as 'n bedreiging ervaar. Indien daar botsings plaasgevind het en die Jode aktief of selfs aggressief opgetree het, het dit boonop nog verdere verbittering veroorsaak. 
Van die meer algemene vorms van vilifikasie was die Joodse weiering om te sosialiseer die een wat die meeste opgeval het en het hulle negatiewe kategorisering van alle nie-Jode besondere aanstoot gegee. Hierdie sosiale aspek was egter die produk van hulle godsdienstige oortuigings. Hoe ons die kwaliteit van die Joodse godsdiens in en rondom die Nuwe-Testamentiese tydvak ook mag beoordeel, en watter ander en mindere oorsake daar ook aangewys sou kon word - op die keper beskou, was die antieke anti-Semitisme die prys wat die Jood betaal het vir die kompromislose wyse waarop hy geweier het om sy geloofsoortuigings en sy unieke identiteit prys te gee.

In hoeverre die oorsake van moderne anti-Semitisme met dié van destyds saamval of nie, sal op eie meriete ondersoek moet word.

\section{Bibliografie}

BELL, H.I. 1924. Jews and Christians in Egypt. Oxford : Oxford University Press.

BOUSSET, W. \& GRESSMANN, H. 1966. Die Religion des Judentums im späthellenistischen Zeitalter. Handbuch zum Neuen Testament 21. Tübingen : Mohr (Paul Siebeck). 4. Auflage.

DU TOIT, A.B. 1997. Joodse religieuse uitbreiding in die tydvak rondom die Nuwe Testament. Was die Judaïsme 'n missionerende godsdiens? (In Du Toit, A.B., red. Die leefwêreld van die Nuwe Testament. Handleiding by die Nuwe Testament 2. Halfway House : Orion. p. 495-517.)

DU TOIT, Andrie. 1999. Die aanvang en omvang van anti-Semitisme in die antieke heidenwêreld in en romdom die Nuwe-Testamentiese tydvak. In die Skriflig, 33(1):21-37.

GOODMAN, M. 1986. VI. Apologetics. (In Schürer, E. 1986. [Vermes, G., Millar, F., Goodman, M. final eds.] The history of the Jewish people in the age of Jesus Christ III/1. Edinburgh : T. T. \& Clark. New English edition, rev. and ed. 1986. p. 595-616.)

HEINEMANN, I. 1931. Antisemitismus. (In Wissowa, G., Kroll, W. e.a., Herausg. Paulys Real-Encyclopädie der classischen Altertumswissenschaft. Neue Bearbeitung Supplementband V. Stuttgart : Druckenmüller. Kol. 3-43.)

HOLSTEN, W. 1957. Antisemitismus. (In Von Campenhausen, H., Dinkler, E. e.a., Herausg. Die Religion in Geschichte und Gegenwart I. Tübingen : Mohr [Paul Siebeck]. kol. 456459.)

LEIPOLDT, J. 1950. Antisemitismus. (In Klauser, Th. Herausg. Reallexikon für Antike und Christentum 1. Stuttgart : Hiersema. kol. 469-476.)

SEVENSTER, J.N. 1975. The roots of pagan anti-Semitism in the Ancient World. Supplements to Novum Testamentum 41. Leiden : Brill.

STERN, M. 1976. The Jews in Greek and Latin literature. (In Safrai, S. \& Stern, M., eds. The Jewish people in the first century. Compendia rerum Iudaicarum ad Novum Testamentum I/2. Assen/Amsterdam : Van Gorcum. p. 1101-1159.)

STERN, M. ed. 1980. Greek and Latin authors on Jews and Judaism II. Jerusalem: Israel Academy of Sciences and Humanities.

TCHERIKOVER, V.A. \& FUKS, A. et al., eds. 1957-1964. Corpus Papyrorum Judaicarum. Cambridge Mass. : Harvard University Press. 